\title{
EDITORIAL: THE FUTURE OF HUMANITARIAN ACTION
}

What evolution and underlying trends influence the future of humanitarian action and its ability to respond to the crises of tomorrow? Since the end of the Cold War, humanitarian activity has grown exponentially to the point that, given the development of such organizations in number, weight, and professionalization, it is now possible to speak of a 'humanitarian sector' or an 'industry'. ${ }^{1}$ Polymorphic and complex, this sector is composed of different systems or 'networks of networks' with no central governance. We see three main components to this sector today: non-governmental organizations of extremely diverse size and missions, the United Nations humanitarian agencies, and finally, the components of the International Red Cross and Red Crescent Movement. The largest of these organizations, whose headquarters are all in the Western world, manage large and constantly increasing budgets, and exercise an influence that, while fluid, is nonetheless real and one of a truly international civil society.

Several factors today seem to demonstrate profound changes in the humanitarian sector. These are factors related first to the development of crises and vulnerabilities and the risks that are emerging, second to the environment around humanitarian action and the contemporary challenges to compliance with humanitarian principles, law, and access to victims, and third to new methods and changes in the composition of the sector itself.

In this edition, the Review gives the floor to representatives of a number of humanitarian organizations and research centres to discuss each of these three aspects of change that we think are critical to the future of humanitarian action.

\section{New threats, new responses}

While conflicts, in particular non-international ones, still represent a major cause of suffering, humanitarian action also responds with increasing frequency to disaster situations, natural or massive technological catastrophes, which have worsened in terms of frequency and magnitude. ${ }^{2}$

The basic idea behind the humanitarian approach is that human suffering knows no borders and, that in dealing with crises, not all countries seem to be in the same boat. Southern countries, more vulnerable to climate change, pay the price of the ecological bill for the development of the powers of the 'North'. In addition, those who live in the slums of Port-au-Prince or the farmers of the Indus Valley are 
just as much the victims of earthquakes or floods as they are of poor infrastructure, a lack of local relief capacity, and governance problems. The map of climatic risks is thus often overlapped by patterns of political instability, chronic insecurity, and underdevelopment. The line between crisis response and long-term development is consequently unclear, particularly in the context of chronic conflict (for example, in Afghanistan, Somalia, and the Democratic Republic of Congo). One uses the term 'complex emergencies' to emphasize the interdependence of the factors governing the vulnerability of populations. Nevertheless, the earthquake in Japan and the nuclear crisis that the tsunami triggered remind us that, in certain circumstances, even rich countries are not immune from crisis, and that their technological superiority can be intricately related to their weaknesses.

The root causes of conflicts between nations have not all been extinguished - far from it. Tensions around Iran, the two Koreas, and both Sudans are just some examples of political and humanitarian fault lines. Nor have noninternational armed conflicts decreased in frequency and gravity. In fact, most conflicts today have a long history and some are seemingly intractable, while the popular uprisings in the Arab world (and the repression that they have encountered) have caused new outbreaks of violence.

Finally, whether manmade or not, whether they strike the richest or the poorest, crises of political, climatic, epidemiological, or tectonic origins affect communities that are increasingly populated and urbanized, the city acting as an amplifier to the vagaries of nature and war. ${ }^{3}$ Faced with these multiple causes, planning the humanitarian response becomes more demanding and difficult to implement.

\section{Humanitarian principles put at test}

After giving an overview of the risks to populations and possible response strategies, this edition of the Review examines in detail some of the challenges to the principles of humanitarian action that have arisen in recent years, particularly in terms of the manipulation of humanitarian actors or viewpoints for political ends and the consequences that this has for access and perceptions. The future of humanitarian

1 ALNAP refers to a 'system', see, The State of the Humanitarian System, Paul Harvey et al., 2010, available at: http://www.alnap.org/forum/post/60.aspx (last visited 20 December 2011). For a statistical evaluation of the volume and evolution of humanitarian aid, of its principal donors and recipients in 2011, see Global Humanitarian Assistance (GHA) Report 2011, Development initiative, available at: www.globalhumani tarianassistance.org (last visited 20 December 2011).

2 The frequency and intensity of catastrophes continue to grow. Thus, in 1975, there were 78 catastrophes recorded in the world, whereas there were 385 in 2011 (statistics and tendencies cited by ECHO, available at: http://ec.europa.eu/echo/about/presentation_en.htm (last visited 20 December 2011)). See also M. Webster et al., 'The humanitarian response costs of climate change', Feinstein International Center, 2009, available at: http://www.unisdr.org/files/8058_Feinstein Tuftsclimatechange.pdf (last visited 20 December 2011).

3 See particularly the thematic edition of the Review on urban violence, Vol. 92, No. 878, 2010. For the humanitarian response in urban environment, see, for example, Inter-Agency Standing Committee, 'IASC Strategy: Meeting Humanitarian Challenges in Urban Areas', IASC, 2010, p. iii. 
action is also conditioned by military, political, or civilian actors who can not only facilitate but also manipulate or obstruct humanitarian action.

Humanitarian actors, which are much more numerous and present in more areas than in the past, are more exposed to criminal attacks by uncontrolled groups and individuals taking advantage of lawlessness. The fact that most of today's conflicts are non-international in nature complicates access to victims: there has been an increase in fragmentation of armed groups in these conflicts and some of them reject any involvement of foreign actors. In turn, states are often reluctant to allow humanitarian actors to operate on their own territory and may impede dialogue with armed groups that they characterise as terrorist or criminal. Given the risks, humanitarian aid is sometimes conducted through local intermediaries, without the presence of foreign personnel. For example, many humanitarian operations in Somalia are conducted by 'remote control'.

Nevertheless, in situations of armed conflict, the action of impartial humanitarian organizations is envisaged by international law. In view of this pressing challenge, Switzerland has recently developed means for the promotion to both humanitarian organizations and to parties to conflicts - of the rules allowing access. ${ }^{4}$

Among the challenges to humanitarian action in conflict situations is the question of the perception by parties to the conflict of humanitarian actors, their activities, and the law. This question of perception is not just one of acceptance in conflict zones. It also arises in public opinion and among policy-makers of the great powers, particularly the United States. Often described as obsolete or irrelevant, international humanitarian law has been particularly tested during the last decade, marked by the 'global war on terror'. The rhetoric of this confrontation has excluded neutral humanitarian space between the coalition of states involved, and the armed groups and terrorist organizations. This question of perception is likewise discussed in the current edition.

Recent crises have also seen a growing number of states entering the humanitarian field, showing more concern towards their own populations. Furthermore, states that are newcomers in humanitarian action, such as Brazil, China, Turkey, and Saudi Arabia, are beginning to integrate international solidarity as part of their foreign policy. In so doing, they define the humanitarian response in their own terms, challenging the de facto monopoly of Western organizations. Their conceptions of 'humanitarianism', their motives for supporting aid, and the terms of their support reflect a humanitarian approach different from that of established organizations and donors and more concerned with respecting the sovereignty of the state receiving the aid. In a world that has become multipolar, this change in the structure of the humanitarian sector presents both challenges and opportunities for the traditional Western actors.

4 Swiss Federal Department of Foreign Affairs, Humanitarian Access in Situations of Armed Conflict: Handbook on the Normative Framework, and Humanitarian Access in Situations of Armed Conflict: Field Manual, available at: http://www.eda.admin.ch/eda/en/home/doc/publi/phumig.html (last visited December 2011). This work is also presented in the current edition. 
Another challenge to principled humanitarian action is the continuous tendency by some states and armed groups to use it for political purposes or to control, or even prevent, the action of foreign humanitarian actors perceived as subversive or unwilling to submit to political injunctions. As we have already mentioned in previous editions of the Review, ${ }^{5}$ the states involved in conflicts in Iraq and Afghanistan have adopted a 'comprehensive approach' against the insurgency: both development efforts and humanitarian assistance to local populations are conducted in parallel with, or in continuation of, combat operations against insurgents. Some humanitarian actors have been asked to participate in the 'stabilization' of Afghanistan or Iraq. They have thus risked putting into question their independence and their neutrality. Many humanitarian actors and researchers have warned, including in the Review, ${ }^{6}$ against the danger engendered by this type of action of confusing and mixing humanitarians with the military. This approach may be questionable in terms of principles and perception, but it may also turn out to be inefficient, if it fails to win active and sustainable support from the population.

As was recently the case in Libya, states can also call on the need to use force to protect civilian populations. Paradoxically, when military operations present 'humanitarian' objectives, there is a high risk that victims will be designated as 'good' or 'bad'. The use of force to protect civilian populations is also likely to create an amalgam between humanitarian and military action in the eyes of the state against which the battle is being waged. The NATO intervention in Libya - portrayed as a 'humanitarian war' and supported by the concept of the 'Responsibility to Protect' - has contributed to casting doubts about the true nature of the humanitarian endeavour.

While tensions between humanitarian and political actors can be particularly acute in times of conflict, natural disasters also present challenges to organizations' access to, and co-ordination with, local authorities, especially when they hit areas already marked by poverty and/or violence. The massive floods that devastated Pakistan in 2010 affected over 20 million people in a country struggling with several armed groups and having to manage a serious problem of internally displaced persons. Besides the response of international organizations and nongovernmental organizations, the Pakistani army was immediately mobilized to respond to the crisis. There are several lessons to be learnt from the experience of humanitarian actors in their co-ordination with the Pakistani authorities, as discussed by one of the contributions in this edition.

5 See 'Conflict in Afghanistan (I)' and 'Conflict in Afghanistan (II)', Vol. 93, Nos 880 and 881 in International Review of the Red Cross. Also see 'Understanding armed groups and the applicable law', and 'Engaging Armed Groups', Vol. 93, Nos. 882 and 883 of the International Review of the Red Cross.

6 See, particularly, Antonio Donini, 'Between a rock and a hard place: integration or independence of humanitarian action?', in International Review of the Red Cross, Vol. 93, No. 881, 2011, pp. 141-157; Fiona Terry, 'The International Committee of the Red Cross in Afghanistan: reasserting the neutrality of humanitarian action', in International Review of the Red Cross, Vol. 93, No. 881, 2011, pp. 173-188. 


\section{Changing actors and evolving practice}

Finally, the humanitarian sector itself is also changing in its composition and practice. The last part of this edition relates to key internal and external developments affecting humanitarian actors and their methods.

Following the rise of Western humanitarian organizations during the 1990s, there has been a new wave of humanitarian actors, this time coming from emerging countries. Donors, organizations with an international missionincluding Islamic-inspired organizations - and local movements of citizens and diasporas are increasingly present and visible in crisis response. In addition, the exemplary solidarity of Tunisians vis-à-vis the refugees during the crisis in Libya reminds us that the first acts of assistance generally are the work of the population itself. Support for local capacity-building can play a greater role in the international response, in the name of efficiency. It is also a model promoted by the concerned states, as it is perceived as being more respectful of their sovereignty. However, the model of intervention for humanitarian organizations generally remains that of the unilateral deployment of Western expertise to support the victims of the 'South'. Besides the public intentions to strengthen partnerships, organizations are still struggling to change their practice in this area.

The performance of humanitarian organizations is regularly the object of criticism - and even more of self-criticism - especially during major crises that mobilize international solidarity. Thus, the entire humanitarian sector has been blamed for poor response and co-ordination of the response to the earthquake in Haiti and the floods in Pakistan. In other contexts, such as recently in Libya, it was rather the inability of most organizations to operate in an arena of conflict that called for the sector to reflect critically on its access to populations. The global economic crisis has affected aid funding for many organizations, while donor pressure demanding better performance has increased. ${ }^{7}$ Organizations are becoming more professional ${ }^{8}$ in order to meet the need for transparency and to respond to concerns to provide the best response for victims. Over time, the sector has changed dramatically by acquiring training, procedures and standards, and mechanisms of assessments and certifications.

Another developing method is that of 'humanitarian diplomacy'. Henry Dunant is certainly the precursor of this practice since, as a private citizen, he created an international movement that persuaded the greatest powers of his time to adopt the first Geneva Convention, thus laying the foundation not only for the Movement of the Red Cross and Red Crescent but also for international humanitarian law. The Movement in general, and the ICRC in particular, already

7 The UK Department for International Development (DFID) has even published its own classification of these organizations. See DFID, The 2011 Multilateral Aid Review, available at: http://www.dfid. gov.uk/what-we-do/how-uk-aid-is-spent/a-new-direction-for-uk-aid/multilateral-aid-review/ (last visited December 2011).

8 On professionalization of humanitarian action, see Peter Walker, 'Professionalizing the humanitarian sector: a scoping study', Feinstein International Center, Tufts University and Catherine Russ, RedR UK Report, commissioned by ELRHA, April 2010. 
have a highly developed method of practising humanitarian diplomacy. ${ }^{9}$ However, it still remains relatively unknown beyond the Movement. In including a contribution on humanitarian diplomacy in this edition, the Review aims to improve the understanding and recognition of this practice.

Since the late 1980s, communication and information technologies have profoundly changed the way in which humanitarian action is perceived and conducted. The immediacy of information on major world crises (the so-called 'CNN effect') has contributed to reinforcing the importance of the humanitarian response. A new revolution is being realized through the widespread use of communication technology both by the humanitarian organizations and by the beneficiaries. Geo-localization and the use of satellite imagery can detect population movements, measure the extent of a disaster, or confirm the existence of atrocities. Internet access helps people who have been separated to find each other more easily and to mobilize volunteers around the world. The widespread use of mobile phones allows people to communicate their needs or call for help. These technologies are also increasingly used in overcoming problems of access and security, and in facilitating the conduct of operations by 'remote control'. They have greatly reduced the distance between the headquarters of organizations and teams deployed in the most remote places. New information technologies could signify profound changes for the sector with the emergence of new actors, allowing victims themselves to articulate their needs thus creating, de facto, a greater accountability for organizations.

'As for the future, your task is not to foresee it, but to enable it', wrote Antoine de Saint-Exupéry in The Wisdom of the Sands (1948). Nobody predicted the violent shocks that have crossed the Arab world for over a year, or that a tsunami would result in the questioning of nuclear power in Japan. Unpredictability is more than ever the rule in the humanitarian field, and there can be no question either of predicting or of preventing future crises but rather of preparing for them. Anticipating the worst situations is essential to saving lives. The ability of humanitarian actors to aid the victims of tomorrow will depend on their ability to improve their tools of preparation and rapid response. Because of the high stakes and the influence acquired by the non-governmental sector, the question of the future of humanitarian action goes beyond the introspective debate of a corporation on its own 'business model' (to use the expression of the World Economic Forum ${ }^{10}$ ), being open to all practitioners and researchers interested in international

9 See, for instance, Marion Haroff-Tavel, 'The humanitarian diplomacy of the International Committee of the Red Cross', in African Yearbook of International Humanitarian Law, 2006, pp. 1-16.

10 See the World Economic Forum's Global Agenda Council on Humanitarian Assistance Report, 'A new business model for humanitarian assistance’, 2009, available at: http://www.international-alert.org/ resources/publications/new-business-model-humanitarian-assistance (last visited December 2011). 
issues. In the future, the Review will continue to reserve a part of its pages for discussions on contemporary challenges to the humanitarian response to crises.

During the last twenty years, humanitarian action has ceased being a simple epiphenomenon of international relations. It has gained a real influence. It has also become a support for the projectionist will of certain states, including some emerging countries. Its future will depend on the evolution of crises and of political and military actors, but also on its own ability to enhance its quality, its principles, and in particular its independence vis-à-vis political and armed actors, and its accountability vis-à-vis donors and recipients.

While there are many pressures and changes in external factors in the field, there are also internal risks. The ongoing professionalization should not necessarily mean the growth of bureaucratization, even if that risk exists. Nor does it necessarily entail copying the recipes of private sector management. As a victim of its own growth, one of the most pernicious risks for the humanitarian sector is that, by creating large-scale administration or by copying the multinationals, it will come to identify itself through its structure rather than its humanitarian mission.

Indeed, acting as a humanitarian professional cannot be reduced to a series of practical and technical skills. The task is first and foremost to recognize the humanity in each one of us, as remote and different as we may be, and most importantly to refuse to remain a spectator when this humanity is denied or violated.

Vincent Bernard Editor-in-Chief 